\title{
The associations between socioeconomic status and obesity in Korean children from 1998 to $2009^{*}$
}

\author{
So-Young Nam, Soo-Kyung Lee ${ }^{\#}$ \\ Department of Food and Nutrition, Inha University, Incheon, Korea; ${ }^{\#}$ Corresponding Author: skleenutrition@inha.ac.kr
}

Received 31 August 2013; revised 8 October 2013; accepted 15 October 2013

Copyright (C) 2013 So-Young Nam, Soo-Kyung Lee. This is an open access article distributed under the Creative Commons Attribution License, which permits unrestricted use, distribution, and reproduction in any medium, provided the original work is properly cited.

\begin{abstract}
Increasing interests have been shown in associations between socioeconomic status (SES) and obesity in relation to health inequality. The research objectives were 1) to examine associations between SES and child obesity (including overweight) in Korea over 10 years and 2) to explore possible underlying mechanisms of relationships between SES and obesity. This study used the nationally representative data (KNHANES) from 1998, 2005, to 2009. Children (10 - 18 year-old) were grouped by household income (low, middle-low, middle-high and high) adjusted for the number of family members. Z-scores of height, weight, and BMI for each child were calculated from measured anthropometric data using the 2007 Korean national growth charts. No statistically significant associations were found, however, changes in association patterns were noted. The lower SES group showed shorter height as well as lighter weight among Korean children. More research should be conducted to understand the effects of socioeconomic status on child obesity.
\end{abstract}

Keywords: Socioeconomic Status; Obesity; Korea; Children

\section{INTRODUCTION}

Obesity in children has been increasing worldwide [1, 2] and has emerged as a health issue. Childhood obesity is important because it negatively affects children in many aspects of life and because pediatric obesity is linked to a risk to obesity $[3,4]$ and chronic disease such as type 2 diabetes [5] and cardiovascular disease [6,7] in

\footnotetext{
${ }^{*}$ Conflict of Interest: The authors have no conflict of interest to report.
}

adulthood.

The nature of associations between socioeconomic status (SES) and obesity has been researched in relation to health equality [8]. The different results, however, have been reported depending on the industrial development status of a country [9-16]. Previous studies reported that inverse associations between obesity and SES are often found in developed countries. That is, individuals with low SES are at increased risk of obesity than those with high SES. On the other hand, individuals with high SES tend to be more obese than those with low SES in developing countries. Although Korea is a nation that successfully transited from developing to developed stage of economic development, only a few studies [17-19] have monitored the relation between SES and obesity, especially among children. In addition, the mechanisms of associations between SES and obesity remain to be unclear.

The objectives of this study were 1) to determine the nature of possible relationships between SES and child obesity (including overweight, BMI $\geq 85$ th percentile of BMI-for-age) in Korea over time and 2) to explore possible underlying mechanisms of relationships between SES and obesity by examining specific relationships of SES with height, weight, and BMI.

\section{SUBJECTS AND METHODS}

Study samples of this study were Korean National Health and Nutrition Examination Survey (KNHANES) from the 1998, 2005, and 2009, which provided nationally representative data [20-22]. KNHANES included data on general characteristics including SES, health behaviors, and health and medical conditions.

This study used household income as an indicator of children's SES because it was the only SES variable consistently available for each child in KNHANES datasets. The household income was adjusted for the number of persons in household. The subjects were grouped into 
quartile as low-, middle low-, middle high-, and highSES group by sex and age of each child [20-22].

The directly measured anthropometric data (height, weight and body mass index (BMI)) were transformed to the age- and sex-specific percentiles based on the 2007 Korean Growth Charts [23]. The children's weight status was classified as obese $\left(\mathrm{BMI} \geq 95^{\text {th }}\right.$ percentile for BMI-for-age or BMI $\geq 25$ ), overweight (BMI $85^{\text {th }}$ to $95^{\text {th }}$ percentile), normal weight (BMI $5^{\text {th }}$ to $85^{\text {th }}$ percentile), or underweight $\left(\mathrm{BMI} \leq 5^{\text {th }}\right.$ percentile) according to the 2007 Korean Growth Charts.

The KNHANES adapted complex sampling design, therefore all statistical analyses were conducted taking into account of sampling strata, cluster, and weight, using SPSS software (version 20.0; SPSS Inc., IBM Corp., $\mathrm{NY}$, USA). $\chi^{2}$-tests were conducted to examine differences of overweight and obesity prevalence among SES groups by sex and age. Multiple logistic regression analysis was conducted to test associations between overweight and obese and SES, adjusting for sex and age. We also examined associations between growth status, such as height z-score, weight z-score, and BMI z-score, and SES using GLM adjusted for sex and age. To test the significance of linear trends, SES group variable was used as a continuous variable. A $P$ value $<0.05$ was considered significant for 2 -sided testing.

\section{RESULTS}

A total of 1654 children ( 853 boys and 801 girls), 921 children (487 boys and 434 girls) 1262 children (655 boys and 607 girls) aged between 10 and 18 were analyzed from the 1998, 2005, and 2009 KNHANES, respectively. The prevalence of overweight and obesity was $13.9 \%$ in $1998,20.5 \%$ in 2005 , and $16.8 \%$ in 2009 . While a few statistically significant differences were found between years in low-middle and high SES group, no clear and statistically significant associations between SES and obesity were observed (Table 1). The linear regression analyses adjusting for sex and age also did not find any significant trend between SES and obesity (Table 2).

Height and weight showed a linear and positive relationship with SES in all three years (Table 2). The trend was statistically significant in year 2005 and 2010 for height ( $\mathrm{p}$-trend $=0.001$ and 0.004 , respectively) and weight (p-trend $=0.05$ and 0.04 , respectively). No such significant relationship was found between BMI z-score and SES groups.

\section{DISCUSSION}

Using nationally representative data over the span of 10 years (1998-2009), this study investigated the relationship between SES and obesity in Korean children who aged 10 - 18. Our findings did not support the previous findings that SES was related to the obesity. In previous studies, SES has been found to be associated with reduced or increased obesity risk depending on country's industrial growth status [9-16]. In the United States, industrialized country, the high SES group was less likely to become obese than the lower SES group $[10,12,14-16]$. On the contrary, developing countries such as Brazil, China, and Russia have seen the positive association between SES level and risk of obesity $[10,12,13]$.

Although the association pattern between SES and obesity in Korea might have changed from the rapid socioeconomic development since 1960s, few studies were conducted to examine relationships between SES and obesity. Studies using the KNHANES reported different results about the association between SES and obesity by sex. For men and boys, SES level was positively associated with overweight $[17,18]$ or was not associated [24]. Among women, low SES group was associated with increased risk for overweight [17,24]. A study with Korean adolescents (12 - 18 years) also found the negative relationship between SES and obesity [19]. This study, however, used self-reported family's SES situation, height and weight rather than directly measured ones, therefore subjective emotions of adolescents might have been reflected in the negative relationships between SES and obesity. This study of children using measured height and weight found no significant associations between SES and obesity. However, the pattern of the association between SES and obesity in Korean children appeared to have changed over the past 10 years, although the association was not statistically significant. A U-shape was prevalent in 1998, but a N-shape was found in most sub-groups in 2005. The year of 2009 showed more diverse patterns of $\mathrm{U}_{-}, \mathrm{N}-$, or $\cap$-shape. It remained to be seen whether the association pattern would be moving to that of the developed nations, a negative linear relationship, and maintain such pattern as seen in the US [25].

Empirical studies investigating the mechanisms of associations between SES level and obesity are rare. A previous study [26] suggested shorter height among lower SES groups as a possible mechanism. This study also observed that height, along with weight, was significantly lower among lower SES group. These two positive associations perhaps resulted in no significant associations between SES and BMI (or obesity). It remains to be seen how the relationships of SES with height and weight would progress in Korea. If the relationship between SES and weight becomes negative, the kind of relationships between SES and obesity seen in developed countries would be observed.

This study was limited by using only one variable, household income, for SES, while other studies $[15,16]$ 


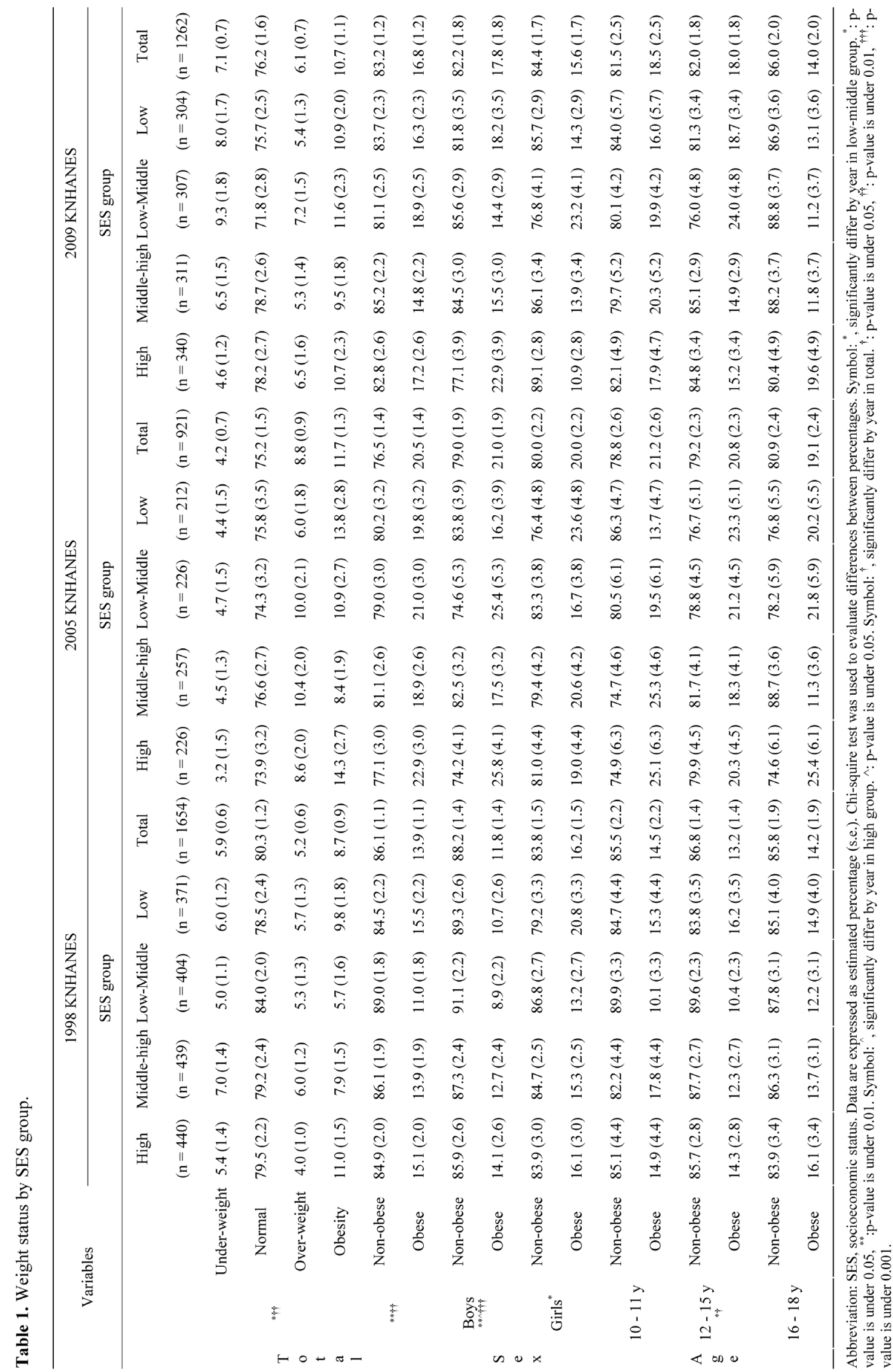




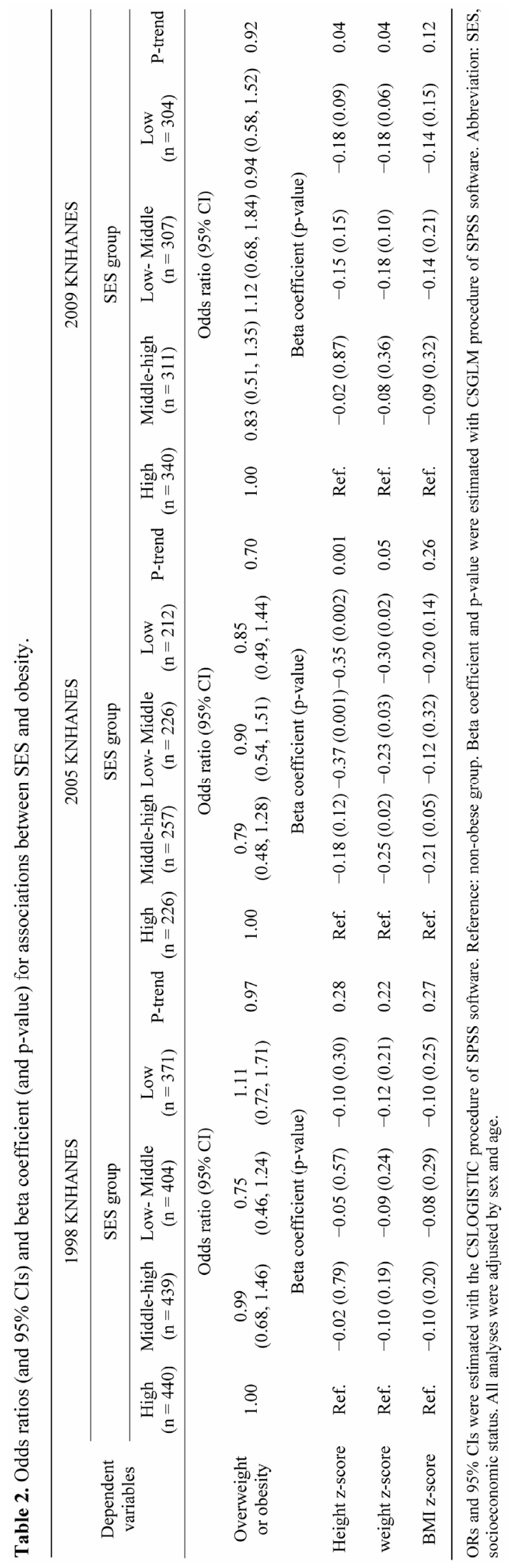


indicated that parental education was perhaps the most important factor among SES variables in relation to obesity. The dataset used in this study did not allow matching parent education information to each child.

This study examined the nature of associations between SES and obesity among Korean children from 1998 to 2009 and explored relationships of SES with height, weight, and BMI to understand possible mechanisms for associations between SES and obesity. No statistically significant associations were found; however, changes in association patterns were noted. The lower SES group showed shorter height as well as lighter weight among Korean children. Further studies would be needed to determine whether and how socioeconomic development would affect associations between SES and obesity.

\section{ACKNOWLEDGEMENTS}

This study was supported by Inha University grant.

\section{REFERENCES}

[1] De Onis, M., Blössner, M. and Borghi, E. (2010) Global prevalence and trends of overweight and obesity among preschool children. The American Journal of Clinical Nutrition, 92, 1257-1264. http://dx.doi.org/10.3945/ajen.2010.29786

[2] Wang, Y. and Lobstein, T. (2006) Worldwide trends in childhood overweight and obesity. International Journal of Pediatric Obesity, 1, 11-25. http://dx.doi.org/10.1080/17477160600586747

[3] Deshmukh-Taskar, P., Nicklas, T.A., Morales, M., Yang, S.J., Zakeri, I. and Berenson, G.S. (2006) Tracking of overweight status from childhood to young adulthood: The Bogalusa Heart Study. European Journal of Clinical Nutrition, 60, 48-57.

http://dx.doi.org/10.1038/sj.ejcn.1602266

[4] Singh, A., Mulder, C., Twisk, J.W.R., Van Mechelen, W. and Chinapaw, M.J.M. (2008) Tracking of childhood overweight into adulthood: A systematic review of the literature. Obesity Reviews, 9, 474-488.

http://dx.doi.org/10.1111/j.1467-789X.2008.00475.x

[5] Power, C. and Thomas, C. (2011) Changes in BMI, duration of overweight and obesity, and glucose metabolism: 45 years of follow-up of a birth cohort. Diabetes Care, 34, 1986-1991. http://dx.doi.org/10.2337/dc10-1482

[6] Srinivasan, S.R., Bao, W., Wattigney, W.A. and Berenson, G.S. (1996) Adolescent overweight is associated with adult overweight and related multiple cardiovascular risk factors: The Bogalusa Heart Study. Metabolism: Clinical and Experimental, 45, 235-240. http://dx.doi.org/10.1016/S0026-0495(96)90060-8

[7] Sinaiko, A.R., Donahue, R.P., Jacobs, D.R. and Prineas, R.J. (1999) Relation of weight and rate of increase in weight during childhood and adolescence to body size, blood pressure, fasting insulin, and lipids in young adults:
The Minneapolis Children's Blood Pressure Study. Circulation, 99, 1471-1476.

http://dx.doi.org/10.1161/01.CIR.99.11.1471

[8] Law, C., Power, C., Graham, H. and Merrick, D. (2007) Obesity and health inequalities. Obesity Reviews, 8, 19-22. http://dx.doi.org/10.1111/j.1467-789X.2007.00312.x

[9] Sobal, J. and Stunkard, A.J. (1989) Socioeconomic status and obesity: A review of the literature. Psychological Bulletin, 105, 260-275.

http://dx.doi.org/10.1037/0033-2909.105.2.260

[10] Wang, Y. (2001) Cross-national comparison of childhood obesity: The epidemic and the relationship between obesity and socioeconomic status. International Journal of Epidemiology, 30, 1129-1136. http://dx.doi.org/10.1093/ije/30.5.1129

[11] Wang, Y., Monteiro, C. and Popkin, B.M. (2002) Trends of obesity and underweight in older children and adolescents in the United States, Brazil, China, and Russia. The American Journal of Clinical Nutrition, 75, 971-977.

[12] Johnson, C.A., Xie, B., Liu, C., Reynolds, K.D., Chou, C.P., Koprowski, C., Gallaher, P., Sprutj-Metz, D., Guo, Q., Sun, P., Gong, J. and Palmer, P. (2006) Socio-demographic and cultural comparison of overweight and obesity risk and prevalence in adolescents in Southern California and Wuhan, China. Journal of Adolescent Health, 39, e1-e8.

[13] Dinsa, G.D., Goryakin, Y., Fumagali, E. and Suhrche, M. (2012) Obesity and socioeconomic status in developing countries: A systematic review. Obesity Reviews, 13, 1067-1079.

http://dx.doi.org/10.1111/j.1467-789X.2012.01017.x

[14] El-Sayed, A.M., Scarborough, P. and Galea, S. (2012) Socioeconomic inequalities in childhood obesity in the United Kingdom: A systematic review of the literature. Obesity Facts, 5, 671-692. http://dx.doi.org/10.1159/000343611

[15] Shrewsbury, V. and Wardle, J. (2008) Socioeconomic status and adiposity in childhood: A systematic review of cross-sectional studies 1990-2005. Obesity, 16, 275-284. http://dx.doi.org/10.1038/oby.2007.35

[16] Bammann, K., Gwozdz, W., Lanfer, A., Barba, G., de Henauw, S., Eiben, G., Fernandez-Alvira, J.M., Kovacs, E., Lissner, L., Morento, L.A., Tornaritis, M., Veidebaum, T. and Pigeiot, I. (2012) Socioeconomic factors and childhood overweight in Europe: Results from the multi-centre IDEFICS study. Pediatric Obesity, 8, 1-12. http://dx.doi.org/10.1111/j.2047-6310.2012.00075.x

[17] Yoo, S., Cho, H.J. and Khang, Y.H. (2010) General and abdominal obesity in South Korea, 1998-2007: Gender and socioeconomic differences. Preventive Medicine, 51, 460-465. http://dx.doi.org/10.1016/j.ypmed.2010.10.004

[18] Kwon, Y., Oh, S., Park, S. and Park, Y. (2010) Association between household income and overweight of Korean and American children: Trends and differences. $\mathrm{Nu}$ trition Research, 30, 470-476. http://dx.doi.org/10.1016/j.nutres.2010.06.015

[19] Oh, I.H., Cho, Y., Park, S.Y., Oh, C., Choe, B.K., Choi, J.M. and Yoon, T.Y. (2011) Relationship between socio- 
economic variables and obesity in Korean adolescents. Journal of Epidemiology, 21, 263-270.

http://dx.doi.org/10.2188/jea.JE20100099

[20] Korea Centers for Disease Control and Prevention (1999) The 1998 Korea national health and nutrition examination survey. KCDC, Korea.

[21] Korea Centers for Disease Control and Prevention (2006) The 2005 Korea national health and nutrition examination survey. KCDC, Korea.

[22] Korea Centers for Disease Control and Prevention (2010) The 2009 Korea national health and nutrition examination survey. KCDC, Korea.

[23] Korea Center for Disease Control and Prevention and the Korean Pediatric Society (2007) 2007 Korean national growth charts. KCDC, Korea.

[24] Joh, H.K., Oh, J., Lee, H.J. and Kawachi, I. (2013) Gen- der and socioeconomic status in relation to weight perception and weight control behavior in Korean adults. Obesity Facts, 6, 17-27. http://dx.doi.org/10.1159/000346805

[25] Rossen, L.M. and Schoendorf, K.C. (2012) Measuring health disparities: Trends in racial-ethnic and socioeconomic disparities in obesity among 2- to 18-year-old youth in the United States, 2001-2010. Annals of Epidemiology, 22, 698-704.

http://dx.doi.org/10.1016/j.annepidem.2012.07.005

[26] Cecil, J., Watt, P., Murrie, I., Wrieden, W., Wallis, D., Hetherington, M.M., Bolton-Smith, C. and Palmer, C.N. (2005) Childhood obesity and socioeconomic status: A novel role for height growth limitation. International Journal of Obesity, 29, 1199-1120. http://dx.doi.org/10.1038/sj.ijo.0803055 